\title{
Diyabetli Bireylerde \\ Covid-19'un Psikolojik Etkileri
}

\section{Doç. Dr. Hamdiye ARDA SÜRÜCÜ ${ }^{1}$, Arş. Gör. Meltem SUNGUR ${ }^{2}$}

'Dicle Üniversitesi Atatürk Sağlık Yüksekokulu Hemşirelik Bölümü, DiYARBAKIR

2Kilis 7 Aralık Üniversitesi Yusuf Şerefoğlu Sağlık Bilimleri Fakültesi Hemşirelik Bölümü, KiLis

DOI: http://dx.doi.org/10.29228/tjdn.52042

\section{Derleme}

Sorumlu Yazar

Meltem SUNGUR

meltem_sungur4633@hotmail.com

\section{Hamdiye Arda Sürücü}

ORCID:0000-0001-7052-1002

\section{Meltem Sungur}

ORCID:0000-0002-2702-5748

\section{Yayın}

Geliş Tarihi: 08-07-2021

Kabul Tarihi: 03-08.2021

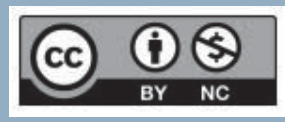

\section{Özet}

Yeni koronavirüs hastalığı 2019 (Covid-19) salgını, hasta ve sağıklı bireylerin birtakım değişikliklere uyum sağlamak zorunda kaldığı, stresli bir durum haline gelmiştir. Kronik hastalığı olan ve aynı zamanda Covid-19'a yatkın olan bireyler, kötü sağık sonuçları açııından yüksek risk altında oldukları için daha fazla stres yaşamaktadırlar. Kronik sağlık sorunları olan diabetes mellitus (DM) tanılı bireyler uygulanan ev karantinaları ve sosyal mesafenin olumsuz zihinsel sağık sonuçları açııından yüksek risk altındadır. Covid-19, diyabet ve ruh sağıı̆ı sorunlarının etkileşimi; diyabetli bireyler için psikolojik olarak mevcut duruma uyum sağlamada zorluklara yol açan karmaşık bir durum yaratmıştır. Bu doğrultuda; derlemede COVID-19'un diyabetli bireyler açııından psikolojik etkilerine değinilmiştir.

Anahtar sözcükler: Covid-19; Diabetes Mellitus; Psikolojik etkiler; Stres

\section{Abstract}

\section{Psychological Effects Of Covid-19 In Individuals With Diabetes}

The epidemic of novel coronavirus disease 2019 (Covid-19) has become a stressful situation in which sick and healthy individuals have to adapt to some changes. Individuals with chronic illness who are also susceptible to Covid-19 experience more stress because they are at higher risk for poor health outcomes. Individuals diagnosed with diabetes mellitus (DM) with chronic health problems are at high risk for adverse mental health consequences of home quarantines and social distancing. Interaction of Covid-19, diabetes and mental health issues; has created a complex situation for individuals with diabetes, which leads to difficulties in adapting to the psychological situation. In this direction; The psychological effects of Covid-19 on individuals with diabetes are mentioned in this review.

Keywords: Covid-19; Diabetes Mellitus; Psychological effects; Stress.

\section{Giriş}

Yeni koronavirüs hastalığı 2019 (Covid-19)'un, çıkış noktasının Aralık 2019'da Çin'in Wuhan kentindeki Hunan deniz ürünleri pazarından kaynaklandığı düşünülmektedir. Etken virüs başlangıçta Dünya Sağlık Örgütü (WHO) tarafından "yeni koronavirüs 2019" (2019-nCoV) olarak adlandırıldı, ancak daha sonra uluslararası komite tarafindan "ciddi akut solunum sendromu koronavirüs 2" (SARS-CoV-2) olarak yeniden isimlendirilmiştir (Lotfi ve ark. 2020; Addis ve ark. 2021). Dünya genelinde hemen hemen tüm ülkeler, hastalık yayılımını bildirmiştir (Riou \& Althaus 2020). Covid-19 krizi, hasta veya sağlıklı bireylerin birtakım değişikliklere uyum sağlamak zorunda kaldığı, değişen ve belirsiz duruma karşı dünyanın dört bir yanındaki insanlar için stresli bir durum haline gelmiştir (Kuroda, 2020; Kontoangelos ve ark. 2020). Hastalık; diyabet gibi endokrin sistem, hipertansiyon gibi kardiyovasküler ve solunum sistem hastalıkları gibi kronik hastalığı olan bireylerde daha şiddetli seyretmiştir (Addis ve ark. 2021). Kronik hastalıklar, dünya çapında engelliliğin önde gelen nedenlerinden biri olup yaklaşık üç yetişkinden biri, bir veya daha fazla kronik hastalıktan muzdariptir (Hajat ve ark. 2018). Kronik hastalıkları olan bireyler, sürekli olarak daha sık sağlık hizmetinden faydalanmakta ve hiz- 
metin kesintiye uğraması ile daha kötü sağlık sonuçları ile karşı karşıya kalmaktadır (Kendzerska ve ark. 2021). Kronik hastalıkların yönetiminin karmaşıklığı ve zor oluşu, Covid-19'a bağlı karşılaşılan engeller ile gün yüzüne çıkmıştır (Kendzerska ve ark. 2021). Kronik hastalığı olan ve aynı zamanda Covid-19'a yatkın olan bireyler, kötü sonuçlar açısından daha yüksek risk altında oldukları için daha fazla stres yaşamaktadırlar (Lim ve ark. 2021). Kronik hastalığı olan bireylerde; depresyon, anksiyete ve stres gibi ruhsal sorunlar hastalığa eşlik etmektedir (Kendzerska ve ark. 2021). Amerika'da yapılan kesitsel bir çalışmada, genel popülasyona kıyasla, kronik rahatsızlıkları olan bireylerin, Covid-19 enfeksiyonundan kaynaklanan kötü sağlık sonuçları için daha fazla risk altında olmaları nedeniyle daha yüksek stres seviyeleri yaşadıkları bulunmuştur (Umucu \& Lee 2020). Covid -19 pandemisi sadece fiziksel sağlığı değil, aynı zamanda zihinsel sağlığı ve refahı da etkilemiştir (Fiorillo \& Gorwood 2020; Wańkowicz ve ark. 2021). Kitle iletişim araçları tarafından; yüksek bulaşıcılık, ölüm oranı, Covid-19 enfeksiyonunun olumsuz seyrine yatkınlık oluşturan hastalıklar ve ayrıca sosyal izolasyon, hedefe yönelik tedavi eksikliği ve tıbbi bakıma sınırlı erişim hakkında paylaşılan bilgiler, büyük bir zihinsel yük oluşturmuştur (Wańkowicz ve ark. 2021). Yapılan kesitsel araştırmalar, kronik hastalığı olan bireyler de dahil olmak üzere katılımcıların \%70'inin genel olarak daha az fiziksel aktivite yaptıklarını belirtmiştir (Kendzerska ve ark. 2021). Kronik hastalıkları olan obez bireyler kardiyovasküler, metabolik ve solunum komplikasyonları açısından risk altındadır, bu nedenle daha kötü sağlık sonuçları görülebilmektedir (Kendzerska ve ark. 2021).

Lim ve arkadaşlarının çalışmasında (2021), SARS-CoV-2 enfeksiyonunun neden olduğu Covid-19 hastalığının diyabetli bireylerde daha şiddetli seyrettiği belirtilmişsir (Lim ve ark. 2021). Türkiye'de ulusal çapta yapılan bir çalışmada ise Covid-19 nedeniyle hastaneye yatırılan tip 2 diyabetli bireyler ile diyabeti olmayan bireylerde Covid-19'un etkisi incelenmiştir (Sönmez ve ark. 2021). Çalışmada Covid-19 nedeniyle hastaneye yatırılan tip 2 diyabetliler ile diyabeti olmayan hastalar karşılaştırıldığında; Covid-19 nedeniyle tip 2 diyabetli bireylerde mortalite oranının fazla, hastanede kalış sürelerinin daha uzun ve yoğun bakıma alınma oranlarının ise daha yüksek olduğu belirlenmiştir (Sönmez ve ark. 2021)

Diyabet, bozulmuş glikoz toleransı (IGT) ve bozulmuş lipid ve karbonhidrat metabolizması ile ilişkili heterojen bir sendromdur (Jain ve ark. 2020). Uluslararası Diyabet Federasyonu 2019 güncel diyabet atlası verilerine göre; toplumda 463 milyon yetişkin diyabetle yaşamakta ve bu sayının 2045'te 700 milyona ulaşması beklenmektedir (International Diabetes Federation [IDF]), 2019). Diyabet tanılı birey sayısı yüksekliğini korumaktadır (Jain ve ark. 2020). Diyabetli her 2 kişiden biri (232 milyon) teşhis edilememektedir (IDF, 2019). Türkiye'de 20-79 yaş aralığında yaklaşık 7 milyon kişinin diyabet hastası olduğunu ve bu rakamın yetişkin nüfusun yaklaşık \%15'ine denk geldiğini göstermektedir (Satman ve ark., 2013). Kan glikozu düzeyinin hedeflenen seviyeye getirilememesi sonucu hastalar diyabet ile birlikte hastalığın yol açtığı komplikasyonlarla da baş etmek zorunda kalmaktadır (Lee ve ark. 2016). Tüm bu komplikasyonlar hastanın yaşam kalitesini olumsuz etkilemektedir (Başar \&
Kahraman 2019; Speight ve ark. 2020). Diyabetin tipik komplikasyonlarının (kardiyovasküler hastalık, kalp yetmezliği ve kronik böbrek hastalığı...) varlığı Covid-19 mortalitesini artırmaktadır (Lim ve ark. 2021). Ayrıca glisemik bozulma veya bozulmuş glikoz regülasyonu diyabetli bireylerde Covid-19'un tipik bir komplikasyonudur (Lim ve ark. 2021). Diyabetli bireyler, hastaneye yatırılan Covid-19 hastalarının önemli bir bölümünü oluşturmaktadır (Peric \& Stulnig 2020).

Salgını kontrol altına almaya yönelik alınan sosyal mesafe ve karantina önlemleri, hem nüfus düzeyinde enfeksiyon bulaşmasını kontrol altına almaya, hem de yaşlılar ve uzun süreli kronik hastalığı olan kişiler dahil olmak üzere yüksek riskli ve hassas gruplara yönelik uygulanmıştır. Pandemi sürecinde alınan önlemler arasında okulların kapatılması, sınır kısıtlamaları, tanı konmuş veya şüphelenilen hastaların karantinaya alınması ve 'evde kalma' veya izolasyon politikaları gibi önlemler yer almaktadır (Amerio ve ark. 2020). Yalnızık ve sosyal yabancılaşma, daha kötü psikolojik sağlık (örneğin stres, umutsuzluk ve nörolojik hasar) ile birlikte düşük yaşam kalitesi (örneğin, daha zayıf motor kontrol, daha zayıf kalp sağlığı, uyku bozukluğu ve güç kaybı) ile ilişkilendirilmiştir (Chan ve ark. 2021). Diyabetli bireyler, uygulanan ev karantinaları ve sosyal mesafenin olumsuz zihinsel sağlık sonuçları açısından yüksek risk altındadır. Hızlı Covid-19 bulaşmasının yanı sıra hassas gruplardaki yüksek vaka ölüm oranı, psikopatolojik dekompansasyon riskini artırabilir ve mevcut psikiyatrik bozuklukları şiddetlendirebilir (Serafini ve ark. 2020). Covid-19 sağlık acil durumu ve buna bağlı olarak uygulanan sosyal mesafe önlemleri intiharlara neden olan yalnızlık, umutsuzluk, ölüm kaygısı duygularını teşvik edebilir ve klinik değerlendirmeler ve reçeteler için düzenli ayakta tedavi ziyaretlerine erişim zorluklarını artırabilir (Amerio ve ark. 2020). Diyabetli bireylerin Covid-19 pandemisi sırasında glisemik kontrolün kötüleşmesi, uygun ilaçların bulunamaması, sağlık hizmetlerine erişememe veya Covid-19'a yakalanma ve devamında daha kötü sonuçlar konusunda önemli endişeleri bulunmaktadır (Singhai ve ark. 2020). Diyabetli bireyleri izleyen hekimler, sosyal mesafe ve karantina önlemlerinin glisemik kontrol üzerindeki etkisinin farkında olmalıdır. Pandemi sürecinde; insanları evde kalması için çağrıda bulunmak, normal günlük rutine kıyasla büyük olasılıkla fiziksel egzersiz miktarını azaltacaktır. Hastalar stres ve enfeksiyon nedeniyle oluşan hiperglisemi açısından tehdit altındadır (Peric \& Stulnig 2020).

Diyabet ile yaşamaktan kaynaklanan umutsuz, kızgın veya hüsrana uğramış hissetmek gibi olumsuz duygular'diyabet sıkıntısı veya diyabet distresi' olarak tanımlanmaktadır (Singhai ve ark. 2020). Diyabet sıkıntısı (distresi) tek başına bir psikyatrik durum olmamasına karşın diyabet sıkıntısı diyabetli bireylerde öz bakım davranışlarını ve sağlık personeli ile etkileşimi azaltan, tedavi uyumunu bozan ve yetersiz gelisemik kontrole neden olan bir durumdur (Singhai ve ark. 2020). Joensen vd. (2020)'nin Danimarka'da diyabetli kişilerde Covid-19 pandemisinin psikososyal sonuçlarını değerlendirdiği çalışmada katılımcıların yarıdan fazlasının Covid-19 ile enfekte olursa diyabet nedeniyle aşırı etkilenmekten, yaklaşık üçte birinin diyabet nedeniyle bir risk grubu olarak nitelendirilmekten ve enfekte olursa diyabeti yönetememekten endişe duyduğu belirtilmiş- 
tir. Aynı çalışmada diyabet komplikasyonları ve diyabet sıkıntısı, izole ve yalnız hissetme duyguları ve diyabeti yönetme ile ilişkili davranışları değiştirme gibi durumların hastaların Covid-19 ve diyabet hakkında daha fazla endişe duymalarına neden olduğu belirtilmiştir (Joensen ve ark. 2020). Forde ve arkadaşlarının (2021) yaptığı araştırmaya göre diyabet hemşireleri diyabetli bireylerde psikolojik sorunların (anksiyete, diyabet sıkıntısı ve depresyon) en fazla Covid-19 pandemisi sırasında arttığını bildirmiştir (Forde ve ark. 2021). Covid-19 süreci var olan bir psikiyatrik durum olmamasına rağmen öz bakımın ve sağlık profesyonelleriyle etkileşimin azalmasına, tedaviye uyum eksikliğine ve yetersiz glisemik kontrole neden olabilir (Bahrmann ve ark. 2014). Diyabetli bireylerde algılanan sağlık kaygısı ve hastalık korkusu kendi kendini yönetme yeteneği üzerinde olumsuz etki gösterebilmektedir. Sonuç olarak, stres, yetersiz sosyal destek ve yaşamdaki herhangi bir yeni değişikliğe karşı olumsuz duygular glisemik kontrolü etkileyebilmektedir (Luyckx ve ark. 2010). Yüksek stres düzeyi aynı zamanda diyabetli bireylerin sağlıklı baş etme yöntemlerini kullanmalarını engellemektedir (Singhai ve ark. 2020). Psikolojik stresi artırabilecek risk faktörleri arasında sosyal destek eksikliği, yalnızlık, zihinsel sağlık hizmetlerine sınırlı erişim ve önceden var olan diyabetik mikrovasküler ve makrovasküler komplikasyonların kötüleşmesiyle ilgili endişeler yer almaktadır (Singhai ve ark. 2020).

Fisher ve arkadaşlarının (2020) Covid-19 pandemisinin tip 1 veya tip 2 diyabetli yetişkinler üzerindeki erken etkisini incelediği kohort çaıışmasında; pandemi öncesi ile karşılaştıııldığında pandemi sürecinde bildirilen $\mathrm{HbA} 1 \mathrm{c}$ değerlerinde yükselme olduğu ve bunun yanı sıra yükselen $\mathrm{HbA} 1 \mathrm{c}$ oranları ile diyabetle ilişkili stres düzeyindeki artış arasında önemli bir pozitif korelasyon olduğu belirtilmiştir (Fisher ve ark. 2020). Covid-19'u takiben karantina süreci, insülin enjeksiyon kaynaklarını etkilemedi ancak bu süreçte diyabet bakım ekiplerinin desteğinin olmaması, sağlık hizmetlerine erişimin azalması ve sosyal desteğin azalmasıyla insanları stres ve kaygıya karşı daha savunması hale getirdi (Varshney ve ark. 2020). Bu nedenle, Covid-19, diyabet ve ruh sağlığı sorunlarının etkileşimi, diyabetli bireyler için psikolojik olarak mevcut duruma uyum sağlamada zorluklara yol açan karmaşık bir durum yaratmıştır (Singhai ve ark. 2020). Covid-19'a bağlı diyabete özgü psikolojik sorunlarla ilişkili yeni psikolojik durum; öz-yönetimini sürdürme gayreti diyabetli bireylerde duygusal sıkıntıyı (öz bakım, ilaç tedavisi, Covid-19 davranış değiş̧ikliği ve hijyen uygulamaları dahil), kişisel ve kişiler arası düzeyde psikososyal zorlukları (sosyal mesafeyi korumanın ve kendi kendini toplumdan/ yakın çevreden izole etme isteği) arttırabilir (Mukhtar \& Mukhtar 2020). Ghosh'un (2020)'de Covid-19 salgını sırasında Hindistan'da ülke çapında uygulanan karantinanın tip 2 diyabetli bireylerin yaşam tarzı ve diğer tıbbi sorunları üzerindeki etkilerini araştırdığı çalışmada bireylerin \%87'sinin mental stres yaşadığını belirttiği tespit edilmiştir (Ghosh ve ark. 2020). Addis, Nega ve Miretu (2021) tarafından 422 kişiden oluşan, içerisinde diyabetli bireylerin de olduğu $(\% 20,8)$ kronik hastalığı olan bireylerin, Covid-19 pandemi sürecinin psikolojik etkisinin ve ilişkili faktörlerin araştıııldığı çalışmada hastaların psikolojilerinin \%22,8'inin olumsuz etkilendiği ve yaklaşık dörtte birinin Covid-19 nedeniyle psikolojik sorun yaşadığı, daha uzun süreli kronik hastalığı olan hastaların, hastalık süresi daha kısa olan hastalara göre psikolojik sorunlar yaşama olasılığının daha yüksek olduğu belirlenmiştir. Aynı çalışmada, ileri yaş, kadın cinsiyet, daha uzun hastalık süresi, solunum semptomlarının varlığı ve sosyal desteğin olmamasının, Covid-19'un kronik hastalığı olan hastalar üzerindeki anormal psikolojik etkisi ile önemli ölçüde ilişkili olduğu belirtilmiştir (Addis ve ark. 2021). Covid-19 pandemisinin Hindistan'daki kronik rahatsızlıkları olan insanlar üzerindeki sağlık, psikososyal ve ekonomik etkilerinin araştırıldığı diyabetli bireylerin de dahil edildiği çalışmada bireylerin üçte birinin, karantinalar sırasında önerilen diyet planlarına uymadığı ve meyve-sebze tüketimini azalttığı, yaklaşık üçte ikisinin fiziksel aktivite yapmadığı belirtilmiştir. Aynı çalışmada; bireylerin, yaklaşık üçte ikisi Covid-19 ile ilgili korku/endişe yaşadığı, neredeyse yarısının Covid-19 karantinaları sırasında stresle baş etmede orta düzeyde zorluk yaşadığı, diyabetli ve hipertansiyonlu katılımcıların ise neredeyse tamamının Covid-19 ile enfekte olduklarında kötü sonuç alma riskinin arttığının farkında olduğu ve birçoğunun yürüyüşe veya diğer düzenli egzersizlere çıkmaktan korktuğu belirtilmiştir (Singh ve ark. 2021). Forde ve arkadaşları (2021)'nın diyabet hemşirelerinin Covid-19 pandemisinin diyabetli bireyler üzerindeki etkisini ve Avrupa genelinde diyabet hizmetlerine ilişkin bakış açılarını tanımladığı araştırmada çoğu ülkede diyabet hemşirelerinin diyabetli kişilerin psikolojik sağlıklarına yönelik risklerin daha fazla arttığı görüşünde olduğu ve yanıt veren hemşirelerin yaklaşık yarısı akut hiperglisemide büyük artışlar olduğunu belirtmiştir (Forde ve ark. 2021). Bu çalışma hiperglisemi ile psikolojik sıkıntı arasındaki ilişkiyi desteklemektedir. Fisher, Polonsky, Asuni, Jolly, ve Hessler (2020), Covid-19'un tip 1 veya tip 2 diyabetli yetişkinlerdeki etkisini değerlendirmek için pandemi öncesi ile pandemi sürecini incelendiği bir kohort çalışması yapmışlardır. Çalışmada diyabetli bireylerin pandemi süreci, pandemi öncesi süreç ile karşılaştıııldığında pandemi sürecinde hem tip 1 hem de tip 2 diyabetli bireylerde genel stres düzeyleri ve diyabetle ilişkili stres düzeylerinde artma olduğu bulunmuştur. Ayrıca aynı çalışmada grupların neredeyse yarısı pandemi sürecinin diyabet yönetimini zorlaştırdığını belirtmiştir ( Fisher ve ark. 2020).

\section{Sonuç ve Öneriler}

Psikolojik faktörler insanların enfeksiyon tehdidi karşısında başa çıkma stratejilerini yönetmede önemli bir role sahiptir (W Cullen ve ark. 2020). Covid-19 salgın sürecinde diyabetli bireyler için sağlam bir zihinsel sağlık, psikososyal işlevsellik ve duygusal rahatlık önemlidir. Şiddetlenen psikolojik faktörler hem hastalık semptomlarının hem de komplikasyonlarının kontrol altına alınmasını ve hastalığın yönetimini zorlaştırmaktadır. Diyabetli bireyler Covid-19 hastalığı nedeniyle diyabet sıkıntısı deneyimlemekte ve psikolojik olarak uyumsuzluk yaşamaktadırlar. Fiziksel sağlık sorularının kontrol altına alınmasında zeminde var olan ve salgın ile daha fazla gün yüzüne çıkan psikolojik etkilerin yönetimini içerecek fiziksel sağlık hizmetlerine entegre bir yaklaşımla kapsamlı bir tedavi ve bakım anlayışı benimsenmelidir. Kronik hastalık grubunda yer alan diyabetli hastaların pandemi düzeyinde ki enfeksiyonlarda özellikle 
dikkat edilmesi gereken bir grup olduğu unutulmamalıdır. Diyabetli bireylerde Covid-19 pandemi sürecinin olumsuz psikolojik etkilerini azaltmada evde bakım hizmetleri aracılığıyla gerekli ekipmanların ve hasta eğitimlerinin sağlanması ve diyabet hemşirelerinin diyabetli bireyleri tele-sağlık/bilişim araçları aracılığıyla desteklemesi önerilmektedir. Bu süreçte diyabetli bireylerin sosyal destek açısından güçlendirilmesi için özellikle aile üyelerin bilgilendirilmesi ve destek gruplarına yönlendirilmesi önerilmektedir.

\section{Kaynaklar}

1. Addis, S. G., Nega, A. D. ve Miretu, D. G. (2021). Psychological impact of Covid-19 pandemic on chronic disease patients in Dessie town government and private hospitals, Northeast Ethiopia. Diabetes \& metabolic syndrome, 15(1), 129-135. https://doi.org/10.1016/j. dsx.2020.12.019

2. Amerio, A., Aguglia, A., Odone, A., Gianfredi, V., Serafini, G., Signorelli, C. ve Amore, M. (2020) Covid-19 pandemic impact on mental health of vulnerable populations. Acta bio-medica : Atenei Parmensis, 91(9-S), 95-96. https://doi.org/10.23750/abm.v91i9-S.10112

3. Bahrmann, A., Abel, A., Zeyfang, A., Petrak, F., Kubiak, T., Hummel, J. ve Bahrmann P. (2014) Psychological insulin resistance in geriatric patients with diabetes mellitus. Patient Educ Couns. 94(3), 417-22. doi: 10.1016/j.pec.2013.11.010.

4. Başar, C. ve Kahraman, S. (2019). Diabetes mellitus'lu hastalarda, hastalık tutumlarının kronik komplikasyonlar üzerine etkisinin incelenmesi . Halk Sağlığı Hemşireliği Dergisi, 1(3), 147157. Erişim Adresi: https://dergipark.org.tr/tr/pub/jphn/issue/48387/646487

5. Chan, A., Ho, J., Li, J., Tam, H. L. ve Tang, P. (2021). Impacts of Covid-19 pandemic on psychological well-being of older chronic kidney disease patients. Frontiers in Medicine, 8, 666973. https://doi.org/10.3389/fmed.2021.666973

6. Fiorillo, A. ve Gorwood, P. (2020). The consequences of the COVID-19 pandemic on mental health and implications for clinical practice. European Psychiatry: The Journal of the Association of European Psychiatrists, 63(1), e32. https://doi.org/10.1192/j.eurpsy.2020.35

7. Fisher, L., Polonsky, W., Asuni, A., Jolly, Y. ve Hessler, D. (2020). The early impact of the CO VID-19 pandemic on adults with type 1 or type 2 diabetes: A national cohort study. Journal of Diabetes and its Complications, 34(12), 107748.

8. Forde, R., Arente, L., Ausili, D., De Backer, K., Due-Christensen, M., Epps, A. ve Yoldi, C. (2021). The impact of the COVID-19 pandemic on people with diabetes and diabetes services: A pan-European survey of diabetes specialist nurses undertaken by the Foundation of European Nurses in Diabetes survey consortium. Diabetic Medicine, 38(5), e14498.

9. Ghosh, A., Arora, B., Gupta, R., Anoop, S. ve Misra, A. (2020). Effects of nationwide lockdown during COVID-19 epidemic on lifestyle and other medical issues of patients with type 2 diabetes in north India. Diabetes \& Metabolic Syndrome, 14(5), 917-920. https://doi.org/10.1016/j.dsx.2020.05.044

10. Hajat, C. ve Stein, E. (2018). The global burden of multiple chronic conditions: A narrative review. Prev Med Rep. 12, 284-293. doi: 10.1016/j.pmedr.2018.10.008.

11. International Diabetes Federation. (2019). IDF Diabetes Atlas, 9th edn. Brussels, Belgium: Erişim adresi: https://www.diabetesatlas.org. Son güncellenme tarihi: 12/02/2020. Erişim tarihi: 30.07.2021 Erişim saati:14.50.

12. Jain, A., Chawla, M., Kumar, A., Chawla, R., Grover, V., Ghosh, S., Pandit, N. ve Chawla, P. (2020). Management of periodontal disease in patients with diabetes- good clinical practice guidelines: A joint statement by Indian Society of Periodontology and Research Society for the Study of Diabetes in India. J Indian Soc Periodontol [serial online], 24, 498-524. Erişim adresi: https://www.jisponline.com/text.asp?2020/24/6/498/300720.

13. Joensen, L. E., Madsen, K. P., Holm, L., Nielsen, K. A., Rod, M. H., Petersen, A. A. ve Willaing, I. (2020). Diabetes and COVID-19: psychosocial consequences of the COVID-19 pandemic in people with diabetes in Denmark-what characterizes people with high levels of COVID-19-related worries?. Diabetic Medicine, 37(7), 1146-1154.

14. Kendzerska, T., Zhu, D. T., Gershon, A. S., Edwards, J. D., Peixoto, C., Robillard, R. ve Kendall,
C. E. (2021). The Effects of the Health System Response to the COViD-19Pandemic on Chronic Disease Management: A Narrative Review. Risk Management and Healthcare Policy, 14 575-584. https://doi.org/10.2147/RMHP.S293471

15. Kontoangelos, K., Economou, M. ve Papageorgiou, C. (2020). Mental Health Effects of COViD-19Pandemia: A Review of Clinical and Psychological Traits. Psychiatry Investigation, 17(6), 491-505. https://doi.org/10.30773/pi.2020.0161

16. Kuroda, N. (2020). Mental health considerations for patients with epilepsy during COVID-19 crisis. Epilepsy \& behavior: E\&B, 111, 107198. https://doi.org/10.1016/j.yebeh.2020.107198

17. Lee, Y. J., Shin, S. J., Wang, R. H., Lin, K. D., Lee, Y.L. ve Wang Y. H. (2016). Pathways of empowerment perceptions, health literacy, self-efficacy, and self-care behaviors to glycemic control in patients with type 2 diabetes mellitus. Patient Educ Couns. 99(2), 287-94. doi: 10.1016/j. pec.2015.08.021.

18. Lim, S., Bae, J. H., Kwon, H. S. ve Nauck, M. A. (2021). COVID-19 and diabetes mellitus: from pathophysiology to clinical management. Nature reviews. Endocrinology, 17(1), 11-30. https://doi.org/10.1038/s41574-020-00435-4

19. Lotfi, M., Hamblin, M. R. ve Rezaei, N. (2020). COVID-19: Transmission, prevention, and potential therapeutic opportunities. Clinica Chimica Acta; International Journal of Clinical Chemistry, 508, 254-266. https://doi.org/10.1016/j.cca.2020.05.044

20. Luyckx, K., Seiffge-Krenke, I. ve Hampson, S. E. (2010). Glycemic control, coping, and internalizing and externalizing symptoms in adolescents with type 1 diabetes: a cross-lagged longitudinal approach. Diabetes Care, 33(7), 1424-1429. https://doi.org/10.2337/dc09-2017

21. Mukhtar, S. ve Mukhtar, S. (2020). Letter to the Editor: Mental Health and Psychological Distress in People with Diabetes during COVID-19. Metabolism: Clinical and Experimental, 108, 154248. https://doi.org/10.1016/j.metabol.2020.154248

22. Peric, S. ve Stulnig, T. M. (2020). Diabetes and COVID-19. Wien Klin Wochenschr, 132, 356361 (2020). https://doi.org/10.1007/s00508-020-01672-3

23. Satman, I., Omer, B., Tutuncu, Y., Kalaca, S., Gedik, S., Dinççağ, N., Kubilay, K., ... Tuomilehto, J. (2013) Twelve-year trends in the prevalence and risk factors of diabetes and prediabetes in Turkish adults. European Journal of Epidemiology, 28, 169-180.

24. Serafini, G., Bondi, E., Locatelli, C. ve Amore, M. (2020). Aged Patients With Mental Disorders in the COVID-19 Era: The Experience of Northern Italy. Am J Geriatr Psychiatry, 28(7), 794 795. doi: 10.1016/j.jagp.2020.04.015.

25. Singh, K., Kondal, D., Mohan, S., Jaganathan, S., Deepa, M., Venkateshmurthy, N. S., ... Eggleston, K. (2021). Health, psychosocial, and economic impacts of the COVID-19 pandemic on people with chronic conditions in India: a mixed methods study. BMC Public Health, 21(1), 685. https://doi.org/10.1186/s12889-021-10708-w

26. Singhai, K., Swami, M. K., Nebhinani, N., Rastogi, A. ve Jude, E. (2020). Psychological adaptive difficulties and their management during COVID-19 pandemic in people with diabetes mellitus. Diabetes \& Metabolic Syndrome, 14(6), 1603-1605. https://doi.org/10.1016/j. dsx.2020.08.025

27. Sonmez, A., Demirci, I., Haymana, C., Tasci, I., Dagdelen, S., Salman, S. ve Satman, I. (2021). Clinical characteristics and outcomes of COVID-19 in patients with type 2 diabetes in Turkey: A nationwide study (TurCoviDia). Journal of Diabetes, 13, 585-595.

28. Speight, J., Holmes-Truscott, E., Hendrieckx, C., Skovlund, S. ve Cooke, D. J. D. M. (2020). Assessing the impact of diabetes on quality of life: what have the past 25 years taught us? Diabetic Medicine, 37(3), 483-492.

29. Umucu E. ve Lee, B. (2020). Examining the impact of COVID-19 on stress and coping strategies in individuals with disabilities and chronic conditions. Rehabil Psychol. 65(3), 193-198. doi: 10.1037/rep0000328.

30. Varshney, M., Parel, J. T., Raizada, N. ve Sarin, S. K. (2020). Initial psychological impact of COVID-19 and its correlates in Indian Community: An online (FEEL-COVID) survey. PLoS One, 15(5), e0233874. doi: 10.1371/journal.pone.0233874.

31. Cullen, W., Gulati, G. ve Kelly, B. D. Mental health in the COVID-19 pandemic. QJM. 113(5), 311-312. doi: 10.1093/qjmed/hcaa110.

32. Wańkowicz, P., Szylińska, A. ve Rotter, I. (2021). The Impact of the COVID-19 Pandemic on Psychological Health and Insomnia among People with Chronic Diseases. Journal of Clinical Medicine, 10(6), 1206. https://doi.org/10.3390/jcm10061206 